\title{
Behavior of Dissolved Organic Matter in Coral Reef Waters in Relation with Biological Processes
}

\author{
Mohamed Farook Mohamed Fairoz (Corresponding author), Beatriz E. Casareto \& Yoshimi Suzuki \\ Department of Environment and Energy Systems \\ Graduate School of Science and Technology, Shizuoka University \\ 836, Oya Suruga ku, Shizuoka 422-8529, Japan \\ Tel/Fax: 81(0)54-2384-799Ｅ-mail: fairoz.mfm@gmail.com
}

Shizuoka University Japan was acknowledged for financial support

\begin{abstract}
Behavior of dissolved organic carbon (DOC) and dissolved organic nitrogen (DON) in coral reef waters in relation with biological processes was studied with incubation experiments and field observations in May 2008 and 2009 at the fringing reef of Sesoko Island, Okinawa, Japan. Reef sea water (RSW) and coral mucus added RSW collected from Acropora digitifera (AcrRSW) and Montipora digitata (MonRSW) were incubated for one day in situ and then for 77 days in the laboratory under dark condition. The results indicated that the behavior of DON was different compared to that of DOC in RSW and mucus added (AcrRSW and MonRSW) during dark incubation. Concentration of DON increased from $8.3 \mu \mathrm{M}$ to $11.8 \mu \mathrm{M}$ for AcrRSW and $4.0 \mu \mathrm{M}$ to $15.4 \mu \mathrm{M}$ for MonRSW during dark incubation period. The increasing rates for DON in AcrSRW and MonRSW were $0.05 \mu \mathrm{M}$ day $^{-1}$ and $0.1 \mu \mathrm{M}$ day ${ }^{-1}$ respectively. On the other hand DOC concentration decreased from $129.0 \mu \mathrm{M}$ to $75.0 \mu \mathrm{M}$ for AcrRSW and $75.1 \mu \mathrm{M}$ to $64.7 \mu \mathrm{M}$ for MonRSW, with decreasing rates of $0.7 \mu \mathrm{M}$ day ${ }^{-1}$ and $0.1 \mu \mathrm{M}_{\text {day }}{ }^{-1}$ respectively. We assume that the increase of DON may be determined by difference between rates of inputs of organic matter mainly from mucus and rate of degradation of dissolved organic matter in the water column. These results suggest that recycling of DON is slow than that of DOC in coral reef ecosystem.
\end{abstract}

Keywords: DON, DOC, Coral reef water, Incubation, Coral mucus

\section{Introduction}

Coral reefs in tropical and sub-tropical oceans are biologically diverse ecosystem with high gross primary production (Sorokin, 1995). This high productivity in oligortophic areas with very low nutrients supply might be due to the rapid recycling of organic matter to inorganic forms (Suzuki et al., 2000). In this view point dissolved organic matters as dissolved organic carbon (DOC) and dissolved organic nitrogen (DON) play an important role because it is rapidly consumed and re-mineralized by the microbial community in reef waters. Several studies suggested that dissolved organic carbon (DOC) derived from coral mucus must sustain the high production rates in coral reef waters by promoting microbial growth (van Duyl and Gast 2001, Ferrier-Pages et al., 2000). However the sources and behavior of dissolved organic nitrogen (DON) is often not well described as that of DOC in reef waters due to the limitation of available data until now. Because most of the studies described organic matter in coral reef water relation to the measurement of DOC without DON (Boyer et al., 1997, Van Duyl and Gast 2001, Hata et al., 2002, Wild et al., 2004). They thought the behavior of DON may be similar to that of DOC, therefore it is possible to calculate the concentration, flux and others from the results of DOC using DOC/DON ratio. Suzuki et al., (2000) reported that the behavior of DON was relatively different than that of DOC from the study on the molecular weight of dissolved organic matter in coral reef water. Therefore further studies are necessary to unveil much details of the behavior of DOC and DON in relation with the biological processes.

This paper reports the behavior of DOC and DON in reef sea water in relation with biological processes with incubation experiments and field observation in Sesoko reef waters.

\section{Materials and Methods}

\subsection{Study site and water sampling}

Sesoko reef is located on the west coast of Sesoko Island, Okinawa, Japan (26 $\left.38^{\prime} \mathrm{N}, 27^{\circ} 51^{\prime} \mathrm{E}\right)$. The reef is characterized by a shallow lagoon $(0.2-6.5 \mathrm{~m}$ depth) and a well-developed reef crest, located $150-200 \mathrm{~m}$ from the shore. The live coral community is composed of about $44 \%$ Goniastrea aspera, $21 \%$ Montipora digitata, $7.4 \%$ 
Porites sp., and 2.2\% Acropora digitifera. Sea water samples were collected from three locations; site A (middle of lagoon), site B (located near the entrance of the lagoon) within the Sesoko reef and site C outside the reef (Fig. 1).

\subsection{Sesoko reef water condition}

Reef water from sites A and B at near shore, middle reef and the reef crest, were collected on 9-10 May 2008 $(14: 30,17: 30$ and at 06:00, except for site A, reef crest at 6:00) into 5 liter Nalgene acid clean bottles and sub-samples of $40 \mathrm{ml}$ transfer to amber glass vials for measurement of DOC and DON. Light and temperature in reef water was also registered using in-situ light and temperature sensors (Alec electronics).

\subsection{Incubation experiments}

Incubation experiments were carried out using reef water (site. A or B), open ocean water and coral mucus. Sea water from site B and coral mucus used and from open ocean were used for incubation experiments.

All bottles $\left(\mathrm{Nalgene}{ }^{\circledR}\right)$ and glass vials used for incubation experiments were washed and rinsed with $10 \% \mathrm{HCL}$ and Milli-Q water before use.

Coral mucus was collected from Acropora digitifera (Acr) and Montepora digitata (Mon) coral species. Coral branches were harvested using hammer and chisel and placed the coral branches in cleaned container with $200 \mathrm{ml}$ of RSW to collect coral mucus for addition to RSW during incubation experiment. For pure mucus collection from A. digitifera, coral branches were air exposed (Dumas et al., 1982) into a bacteria free tube.

\section{Experiment I}

Reef sea water from site B (RSW) and coral mucus added RSW were used. Three experimental groups 1 liter of RSW and $950 \mathrm{ml}$ of RSW plus 50ml of AcrRSW and MonRSW were prepared in triplicate. All bottles contain RSW, AcrRSW and MonRSW were arranged to submerge in situ at a $1 \mathrm{~m}$ depth and incubated one day (from $9^{\text {th }}$ May 2008, 15:00 to next day, 15: 00). After incubation in the field all the bottles were transported to laboratory and kept in dark under room temperature for 77 days. Samples were collected at $0,2,4,15$ and 78 days of incubation and concentrations of DOC, DON, DIN and microbial abundance (heterotrophic bacteria, picocyanobacteria and pico-nanoflagellaes) were measured. The change of concentrations of DOC, DON and DIN were calculated from the difference between beginning day (Day 2) and end day (Day 78) of dark incubation. The differences of concentrations between day 2 and day 78 were divided by the number of incubation days to calculate the rates of concentration change.

\section{Experiment II}

Three experimental groups contain 5 liter of reef sea water from site A, site B and open ocean water from site C (OOW) were prepared. All bottles were arranged to submerge in situ at about $1 \mathrm{~m}$ depth and incubated one day (from $21^{\text {st }}$ May 2009, 15:00 to next day, 15: 00) and transported to laboratory to incubate in dark for 14 days. Samples were collected at $0,2,4$, and 15 days of incubation and concentrations of DOC, DON, DIN were measured.

During experiment II, a short degradation was carried out using pure coral mucus collected from Acropora digitifera. $15 \mathrm{ml}$ of collected coral mucus plus $5 \mathrm{ml}$ of RSW in glass vial was incubated in dark for two days (from $21^{\text {st }}$ May 2009). Samples for initial and after two days were collected to measure DOC and DON concentrations.

\subsection{Analytical method}

Samples for dissolved organic matter were transferred to $40 \mathrm{ml}$ cleaned pre-combusted amber glass vials, after passing through pre-combusted $25 \mathrm{~mm} \mathrm{GF} / \mathrm{F}$ filter (Whatman). The sample vials were covered with Teflon-lined caps and stored at $-20^{\circ} \mathrm{C}$ until analysis of DOC, DON and DIN.

DOC and total dissolved nitrogen (TDN) were determined using a total organic carbon analyzer equipped with a total nitrogen unit (TOC V, Shimadzu) following the methods of Suzuki et al., 1993 and UNESCO 1994. DIN was determined with an auto analyzer (TRAACS-2000) following the methods of Hansen and Koroleff 1999. DON concentration was calculated by subtracting the total dissolved inorganic nitrogen $\left(\left[\mathrm{NO}_{2}+\mathrm{NO}_{3}+\mathrm{NH}_{4}\right]\right)$ or DIN from the concentrations of the total dissolved nitrogen (TDN).

Microbial abundance was measured after staining the sample (preserved in Glutaraldehyde) using DAPI (4', 6-diamino-2-phenylindole) under epi-florescence microscope (Nikon- Eclipse) following the method of Porter and Feig 1980.

Nitrogen and carbon biomass of heterotrophic bacteria, Pico-cyano bacteria and heterotrophic nano flagellates 
were calculated according to Casareto et al., 2000 and Houlbreque et al., 2004.

\section{Results}

\subsection{Sesoko reef water condition}

Temporal variations of DOC and DON in Sesoko during the sampling period are shown in Fig. 2. The maximum light intensity at day time was $2024 \mu \mathrm{M} \mathrm{cm}^{-2} \mathrm{~s}^{-1}$. The average temperature recorded during the sampling period was $25.5^{\circ} \mathrm{C}$ with a diurnal variation of $\pm 2{ }^{\circ} \mathrm{C}$. Concentrations of DOC and DON varied from 68.9 to $77.8 \mu \mathrm{M}$ and 3.1 to $4.7 \mu \mathrm{M}$ respectively. The temporal change of DOC: DON ratio $(\mathrm{C} / \mathrm{N})$ was from 15 to 18 (Fig. 2).

\subsection{Incubation experiments}

\section{Experiment I}

Temporal changes of DOC, DON, DOC: DON ratio, DIN concentrations and microbial abundance of experiment are shown in Fig. 3 and Fig. 4 respectively.

During 77 days dark period concentration of DOC in RSW decreased from $70.2 \mu \mathrm{M}$ to $67.3 \mu \mathrm{M}$ with a rate of $0.04 \mu \mathrm{M} \mathrm{C}$ day $^{-1}$. In AcrRSW and MonRSW DOC decreased from $129 \mu \mathrm{M}$ to $75 \mu \mathrm{M}$ and $75.1 \mu \mathrm{M}$ to $64.67 \mu \mathrm{M}$ respectively. The decrease rates for DOC in AcrSRW and MonRSW were $0.7 \mu \mathrm{M}_{\text {day }}{ }^{-1}$ and $0.1 \mu \mathrm{M}$ day $^{-1}$ respectively.

During 77 days dark period the concentration of DON showed slight increase for all treatments. DON concentration in RSW increased from $2.9 \mu \mathrm{M}$ to $4.3 \mu \mathrm{M}$ with rate of $0.02 \mu \mathrm{M}$ day ${ }^{-1}$. DON concentrations in AcrRSW and MonRSW also increased during dark period from $8.3 \mu \mathrm{M}$ to $11.8 \mu \mathrm{M}$ and $4.0 \mu \mathrm{M}$ to $15.4 \mu \mathrm{M}$ respectively. The increase rates for DON in AcrSRW and MonRSW were $0.05 \mu \mathrm{M}_{\text {day }}{ }^{-1}$ and $0.1 \mu \mathrm{M}$ day $^{-1}$ respectively. These results show that the DON concentration increase largely in case of reef waters enriched with coral mucus. Increase of DON concentration for coral mucus added RSW were significantly high compared to increase of DON in RSW (ANOVA, $p<0.05$ ).

The DIN concentration in RSW increased from $0.9 \mu \mathrm{M}$ to $2.1 \mu \mathrm{M}$ with the rate of $0.02 \mu \mathrm{M}$ day $^{-1}$. The increased DIN concentrations in coral mucus added RSW were more higher compared to RSW from (for AcrRSW from $2.2 \mu \mathrm{M}$ to $4.8 \mu \mathrm{M}$ and for MonRSW and $1.2 \mu \mathrm{M}$ to $6.3 \mu \mathrm{M}$ ).

The concentrations of DON and DIN at day 15 for AcrRSW and MonRSW were high. The DON and DIN concentration increased for MonRSW from day 15 to day 78 and the DON and DIN concentration for AcrRSW decreased from day 15 to day 78. The increase of DON and DIN concentrations for AcrRSW, MonRSW and RSW were compared with relation to the difference between the day 2 and day 78 .

The changes of concentrations of DOC and DON were shown by the DOC: DON ratio. The DOC: DON ratio was decreased in RSW from 24.2 to 15.4. The DOC: DON ratio was decreased in AcrRSW from 16.6 to 6.3 and for MonRSW 12.5 to 4.1 .

Microbial abundance increased rapidly during initial 4 days period, and the microbial abundance decreased gradually until $77^{\text {th }}$ day for all experimental groups. Bacteria cell abundance decreased from $8.3 \times 10^{5} \mathrm{ml}^{-1}$ to 1.2 $\times 10^{5} \mathrm{ml}^{-1}$ for RSW. The bacteria cell abundance decreased from $16-19 \times 10^{5} \mathrm{ml}^{-1}$ to the range of $3-6 \times 10^{5} \mathrm{ml}$ ${ }^{-1}$ for RSW with added mucus. Pico-cyano bacteria cells also decreased during dark period for RSW and mucus enriched RSW. HNF abundance increased as the bacteria and picocyanobacteria decrease. Contribution of organic carbon and nitrogen to RSW from microbial biomass was calculated using conversion factors (Table 1). This shows that the possibility of contribution from microbial biomass as carbon and nitrogen source were relatively low.

\section{Experiment II}

DOC and DON concentrations for reef sea water and open ocean water during 14 days degradation (incubation under dark condition) after one day in-situ incubation are shown in Table 2. DOC concentration decreased for site A and site B from $74.3 \mu \mathrm{M}$ to $63.9 \mu \mathrm{M}$ and $69.0 \mu \mathrm{M}$ to $64.1 \mu \mathrm{M}$ respectively. DOC concentration of OOW did not remarkably change compared to the initial concentration and it was $68.3 \mu \mathrm{M}$ to $69.7 \mu \mathrm{M}$ during 15 days. DON concentration increased for site A and site B from $3.9 \mu \mathrm{M}$ to $4.8 \mu \mathrm{M}$ and $3.9 \mu \mathrm{MN}$ to $4.5 \mu \mathrm{MN}$ respectively. Comparing reef sea water (site A and B) with OOW, the concentration of DON was decreased from $4.2 \mu \mathrm{M}$ to $3.7 \mu \mathrm{M}$ during 15 days showing a different pattern, however the initial value of DON concentration was high in OOW (Table 2).

Short degradation during 2 days of coral mucus added reef seawater showed that DOC and DON concentration decreased from $2846 \mu \mathrm{M}$ to $1407 \mu \mathrm{M}$ and $141.1 \mu \mathrm{M}$ to $119.7 \mu \mathrm{M}$ respectively (Table 3 ). The percentage for 
DOC decrease showed that about $50 \%$ decreased from the initial during two days. DON concentration decrease was less than $20 \%$ from the initial.

\section{Discussion}

In this study, the results of Experiment (I) show that the behavior of DON in RSW, AcrRSW and MonRSW during dark incubation process was different from that of DOC (Fig.3). And also we found in Experiment (II) that the behavior of DOC and DON was different for RSW but not for OOW. This suggests that the organic matters which are dissolved in RSW are of different characteristics to that of open ocean. Mucus degradation for two days showed that the DON degradation rate was slower than DOC. Concentration of DOC was decreased about $50 \%$ from the initial but DON concentration decreased less than $20 \%$ from the initial. This is the first report on this difference of behaviors between DON and DOC in relation with biological processes. When considering previous works reported on organic matter contain in reef waters (Boyer et al., 1997, Van Duyl and Gast 2001, Hata et al., 2002, Wild et al., 2004) none of these studies mentioned the behavior of DOC and DON. In these studies dissolved organic matters were described using measurements of DOC, assuming that the behavior of DON is similar to DOC. And also most of work about the DOC was done at the field observation, not incubation (Van Duyl and Gast 2001, Hata et al., 2002, Wild et al., 2004). Among the limited works on DOC and DON, Suzuki et al., 2000 reported on the difference of flux and behavior between DON and DOC based on the molecular size in reef water and open ocean water at the field. They showed that the different behaviors between both components are due to the characteristics and sources in relation with biological process.

The DOC and DON concentrations in reef water at the field (Sesoko reef) showed that the temporal changes of DOC and DON during light hours had similar trends, indicating that $\mathrm{C} / \mathrm{N}$ ratio in temporal changes is nearly constant ranging from 15 to 18 (Fig.2). This result indicated that the changes of DON and DOC concentrations between field observation and laboratory incubation experiment were different. During incubations where we isolated the seawater from the environment and cancelled the physical effects of tides and water mixing, therefore we can assess the biological processes during degradation period under dark conditions. Results showed that degradation of DOC and DON is of different speed, being more rapid in case of DOC and slow for DON.

Present study indicate that the degradation rate of DON is slow than that of DOC. However if we consider only this result, we cannot explain about increase of DON concentrations during degradation processes. We assume that the increase of DON may be determined by the difference between rates of inputs of dissolved organic matter (DOM) mainly from coral mucus and rate of degradation of dissolved organic matter in the water column. These suggest that recycling of DON is slow than that of DOC in coral reef ecosystem.

For confirmation of this assumption we need to study on the lability of the dissolved organic matter in reef waters, in particular the mucus source DOC and DON. Therefore to study the behavior of DON in relation with the biological processes, we should measure directly DON and DOC at the same time.

\section{References}

Boyer, J. N., Fourqurean, J. W., Jones, R. D. (1997). Spatial characterization of water quality in Florida Bay and Whitewater Bay by multivariate analyses: zones of similar influence. Estuaries, 20, 743-758.

Casareto, B.E., Suzuki, Y., Casareto, B. E., and Kurosawa, K. (2000). Particulate organic carbon budget and flux in a fringing coral reef at Miyako Island, Okinawa. Proc. $10^{\text {th }}$ Int. Coral Reef Symp., 1, 568-572.

Daumas R., Galois, R., Thomassin, B., (1982). Biogeochemical composition of soft and hard coral mucus on a new Caledonian lagoonal reef. Proc. $4^{\text {th }}$ Int. Coral reef Symp., 2, $59-68$.

Ferrier-Pages, C., Leclercq, N., Jaubert, J., and Pelegri, S. P. (2000). Enhasment of pico- and nanoplankton growth by coral exudates. Aquat. Microb. Ecol., 21, 203-209.

Hansen, K., and Koroleff, F. (1999). Determination of nutrients. In Methods of seawater analysis. ( ed. By Grasshoff K, Kremling K, Ehrhardt M.). Wiley, Weiheim, pp.159-228.

Hata, H., Kudo, S., Yamano, H., Kurano, N., Kayanne, H. (2002). Organic Carbon flux in Shirano coral reef (Ishigaki Island, Japan). Mar. Ecol. Prog. Ser., 232, 129-140.

Houlbreque, F., Tambulte, E., Richard, C., Ferrier-Pages, C. (2004). Importance of micro-diet for scleractinian corals. Mar. Ecol. Prog. Ser., 282, 151-160.

Porter, K.G., and Feig, Y. S. (1980). The use of DAPI for identifying and counting aquatic microflora. Limnol. and Oceanogr., 25, 943-948. 
Sorokin, Y. I. (1995). Coral reef ecology. $2^{\text {nd }}$ edition, Springer Verlag, New York, pp. 465.

Suzuki, Y., Hedeges, J., Lee, C., Wengersky, P. (1993). On the measurement of DOC and DON in sea water, Mar Chem., 41, 287-290.

Suzuki, Y., Casareto, B. E., Kurosawa, K. (2000). Import and export fluxes of HMW-DOC and LMW- DOC on a coral reef at Miyako Island, Okinawa Proc. $9^{\text {th }}$ Int. Coral Reef Symp., 1,555-559.

UNESCO (1994). Protocols for the Joint Global Ocean Flux study (JGOFS) Core Measurements. IOC report Manuals and Guidelines 29. $170 \mathrm{p}$.

Van Duyl, F. C., and Gast, G. J. (2001). Linkage of small-scale spatial variations in DOC, inorganic nutrients and bacterioplankton growth with different coral reef water types. Aquat. Microb. Ecol., 24, 17-24.

Wild C., Huettel M., Kuelter A., Kremb S. G., Rasheed M.Y.M., and Jorgensen B. (2004). Coral mucus function as an energy carrier and particle trap in the reef ecosystem. Nature, 428, $66-70$.

Table 1. Biomass of bacteria, pico cyanobacteria and pico and nano-flagellates. (a) nitrogen biomass (b) carbon biomass of initial and final for the 77 days of dark period for experiment I (Mean \pm standard deviation of three incubation bottles).

(a)

\begin{tabular}{|c|c|c|c|c|c|c|}
\hline \multirow{3}{*}{$\begin{array}{l}\text { Organism } \\
\text { group }\end{array}$} & \multicolumn{6}{|c|}{ Nitrogen biomass $(\mu \mathrm{M})$} \\
\hline & \multicolumn{2}{|c|}{ RSW } & \multicolumn{2}{|c|}{$\underline{\text { AcrRSW }}$} & \multicolumn{2}{|c|}{ MonRSW } \\
\hline & Initial & Final & $\underline{\text { Initial }}$ & $\underline{\text { Final }}$ & $\underline{\text { Initial }}$ & $\underline{\text { Final }}$ \\
\hline Bacteria & $0.37 \pm 0.1$ & $0.05 \pm 0$ & $0.70 \pm 0.2$ & $0.15 \pm 0.02$ & $0.87 \pm 0.04$ & $0.25 \pm 0.02$ \\
\hline \multicolumn{7}{|l|}{ Pico } \\
\hline cyanobacteria & $0.05 \pm 0$ & 0 & $0.02 \pm 0$ & 0 & $0.04 \pm 0.01$ & 0 \\
\hline \multicolumn{7}{|l|}{ Pico and } \\
\hline nano-flagellates & $0.01 \pm 0$ & 0 & $0.06 \pm 0.02$ & $0.01 \pm 0$ & $0.06 \pm 0.04$ & 0 \\
\hline
\end{tabular}

(b)

\begin{tabular}{|c|c|c|c|c|c|c|}
\hline \multirow{3}{*}{$\begin{array}{l}\text { Organism } \\
\text { group }\end{array}$} & \multicolumn{6}{|c|}{ Carbon biomass ( $\boldsymbol{\mu M})$} \\
\hline & \multicolumn{2}{|c|}{ RSW } & \multicolumn{2}{|r|}{$\underline{\operatorname{AcrRSW}}$} & \multicolumn{2}{|c|}{ MonRSW } \\
\hline & $\underline{\text { Initial }}$ & Final & $\underline{\text { Initial }}$ & Final & $\underline{\text { Initial }}$ & Final \\
\hline Bacteria & $1.6 \pm 0.6$ & $0.23 \pm 0.01$ & $3.10 \pm 1.2$ & $0.66 \pm 0.09$ & $3.81 \pm 0.19$ & $1.09 \pm 0.07$ \\
\hline \multicolumn{7}{|l|}{ Pico } \\
\hline cyanobacteria & $0.8 \pm 0.02$ & 0 & $0.34 \pm 0.05$ & $0.01 \pm 0$ & $0.71 \pm 0.13$ & 0 \\
\hline \multicolumn{7}{|l|}{ Pico and } \\
\hline nano-flagellates & $0.12 \pm 0.03$ & $0.05 \pm 0.02$ & $0.57 \pm 0.15$ & $0.08 \pm 0.04$ & $0.58 \pm 0.03$ & $0.04 \pm 0$ \\
\hline
\end{tabular}


Table 2. Changes in DOC and DON during 15 day incubation with one day in-situ incubation and 14 day incubation in laboratory dark condition for water samples from Sesoko coral reef (site A and site B) and open ocean surface water (site C). Mean values \pm standard deviations from three measurements

\begin{tabular}{|c|c|c|c|}
\hline \multirow{2}{*}{$\begin{array}{l}\text { Location of sea water } \\
\text { collection }\end{array}$} & \multirow{2}{*}{$\begin{array}{l}\text { Time } \\
\text { (Days) }\end{array}$} & \multicolumn{2}{|c|}{ Concentration } \\
\hline & & DOC $(\mu \mathrm{M})$ & $\operatorname{DON}(\mu \mathrm{M})$ \\
\hline & Initial & $68.3 \pm 0.2$ & $4.2 \pm 0.1$ \\
\hline Open ocean & 2 & $69.2 \pm 0.1$ & $3.9 \pm 0.1$ \\
\hline (site C) & 15 & $69.7 \pm 0.1$ & $3.7 \pm 0.1$ \\
\hline Sesoko reef & Initial & $74.3 \pm 0.1$ & $3.9 \pm 0.1$ \\
\hline \multirow[t]{2}{*}{ site A } & 2 & $69.2 \pm 0.1$ & $4.3 \pm 0.1$ \\
\hline & 15 & $63.9 \pm 0.1$ & $4.8 \pm 0.1$ \\
\hline Sesoko reef & Initial & $69.0 \pm 0.1$ & $3.9 \pm 0.1$ \\
\hline \multirow[t]{2}{*}{ site $B$} & 2 & $70.3 \pm 0.2$ & $5.6 \pm 0.4$ \\
\hline & 15 & $64.1 \pm 0.4$ & $4.5 \pm 0.1$ \\
\hline
\end{tabular}

Table 3. Concentrations of DOC and DON for mucus of A. digitifera plus reef water during 2 days degradation. Mean values \pm standard deviations from three measurements.

\begin{tabular}{|c|c|c|}
\hline \multirow{2}{*}{ Time (Days) } & \multicolumn{2}{|c|}{ Concentration $(\mu \mathrm{M})$} \\
\hline & DOC & DON \\
\hline Initial & $2846 \pm 7$ & $141.1 \pm 1$ \\
\hline 2 & $1407 \pm 7$ & $119.7 \pm 2$ \\
\hline
\end{tabular}

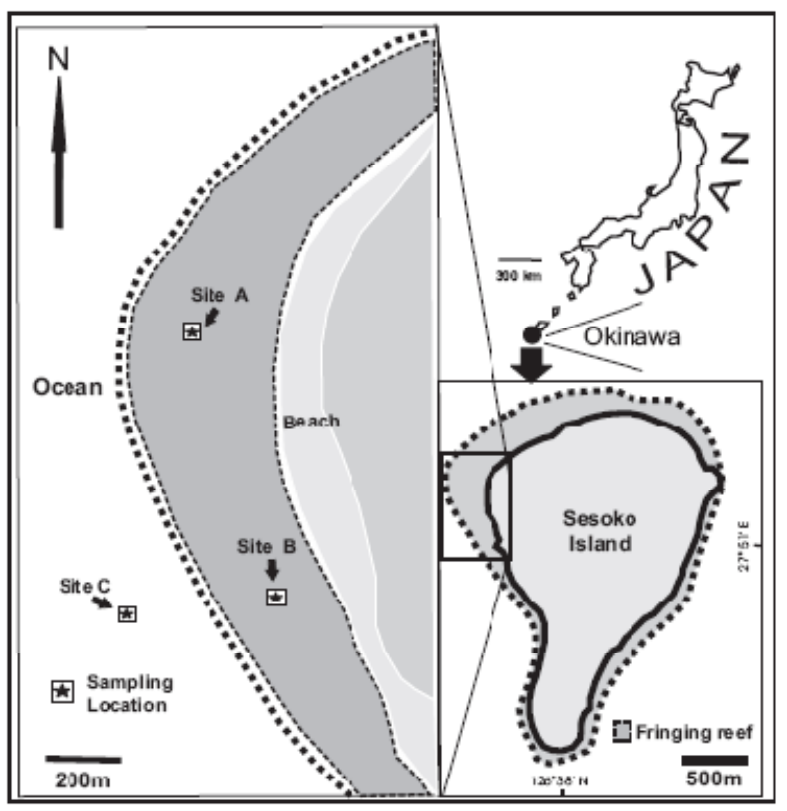

Figure 1. Map of the Sesoko Island, Okinawa, Japan indicating three sampling locations including two locations with the reef (site A and site B) and one location adjacent open ocean water (site C). 

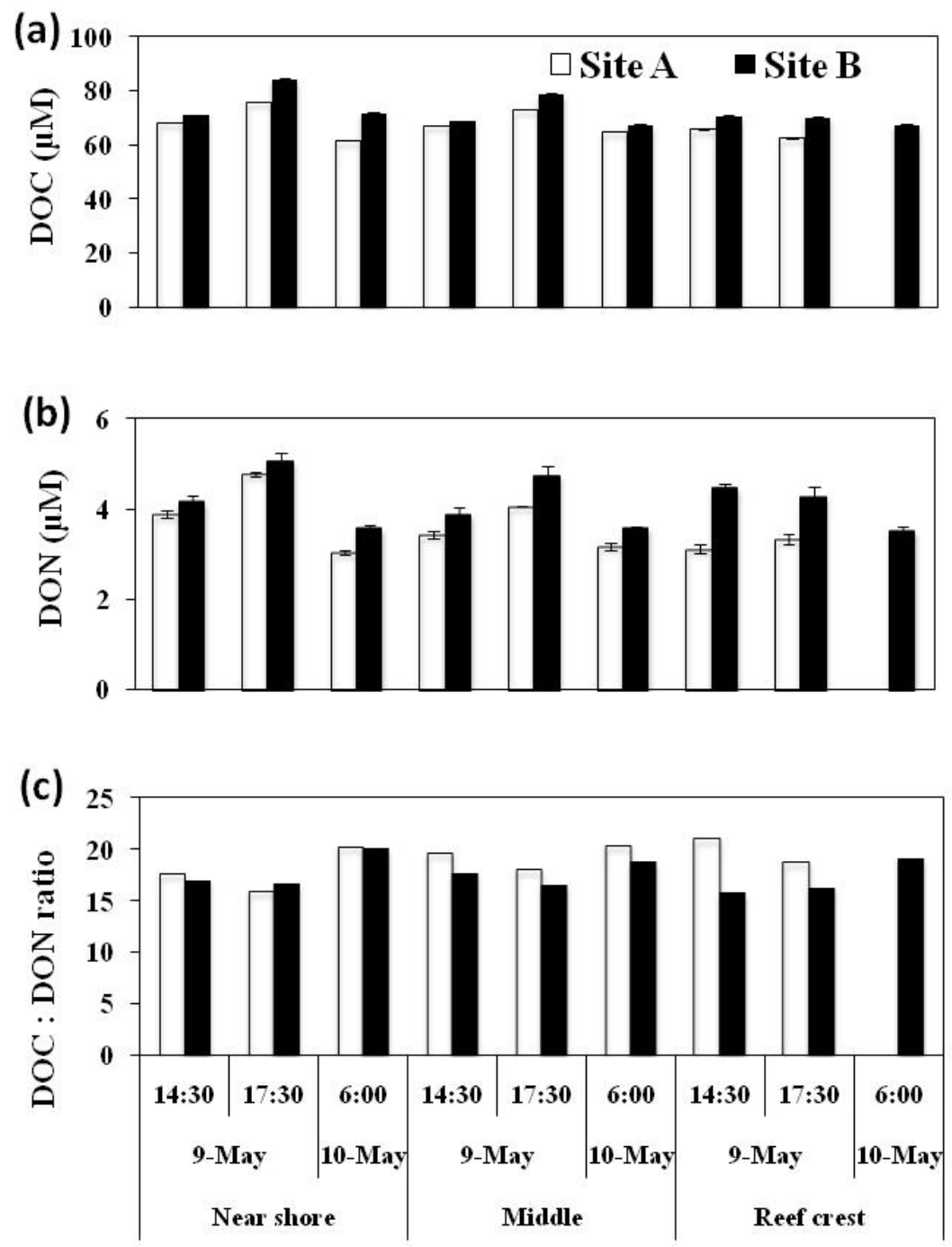

Figure 2. Variation of (a) DON, (b) DOC concentrations and (c) DOC: DON ratio measured for Sesoko coral reef water at site $\mathrm{A}$ and site $\mathrm{B}$ along three different points (near shore, middle and reef crest) during 14:00, 17:00 and following day at 06:00 (except for site A, reef crest) in May 2008. Concentrations indicated with mean values and standard errors. 

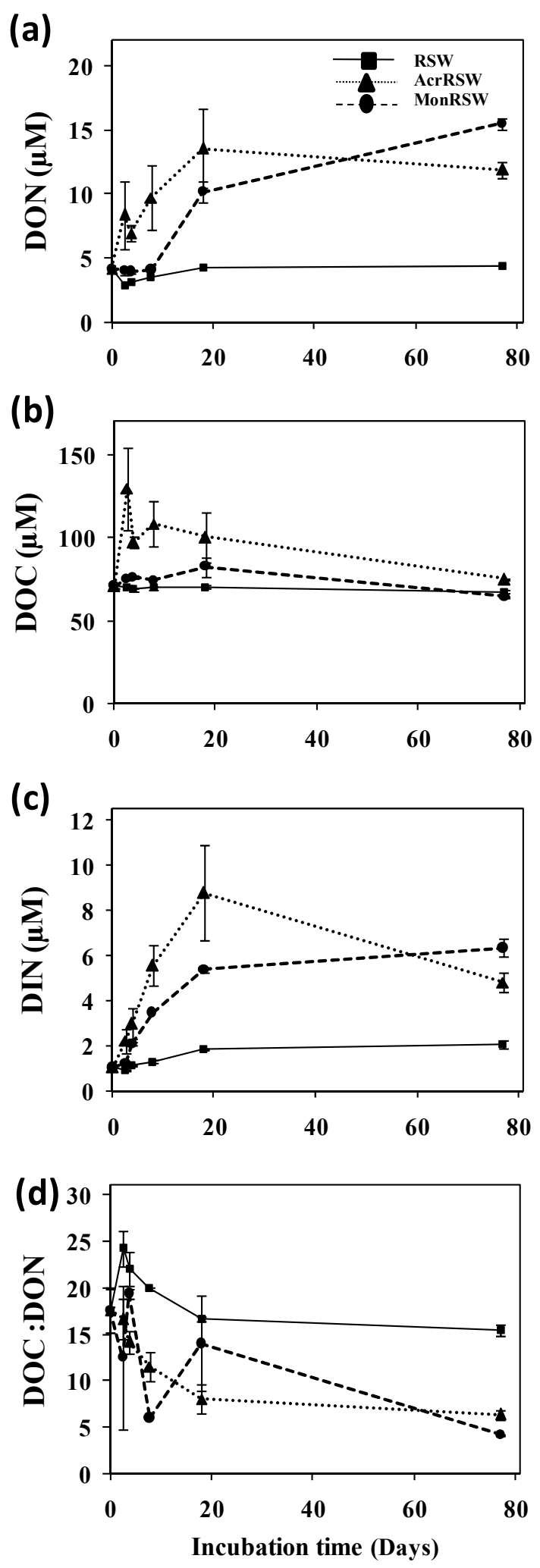

Figure 3. Changes in (a) DON, (b) DOC, (c) DIN concentrations and (d) DOC: DON ratio during 78day incubation period with one day in-situ incubation and 77 days in laboratory dark condition.

\footnotetext{
(RSW - ), and enriched coral mucus from Acropora digitifera (AcrRSW - - - ) and Montepora digitata (MonRSW ...... ). Concentrations indicated by mean with standard error.
} 


\section{(a)}

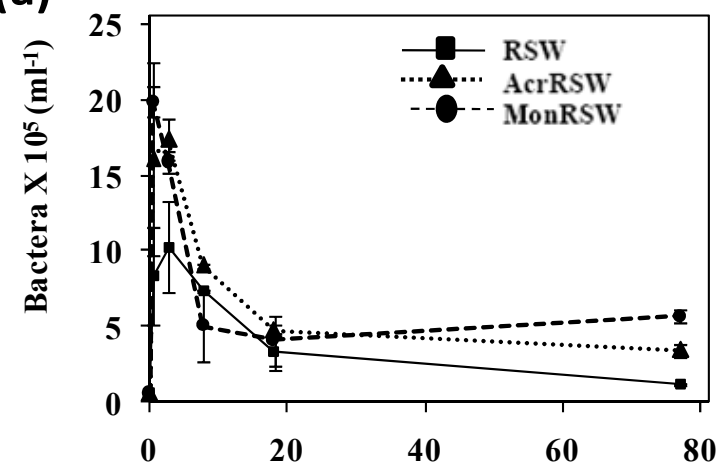

(b)
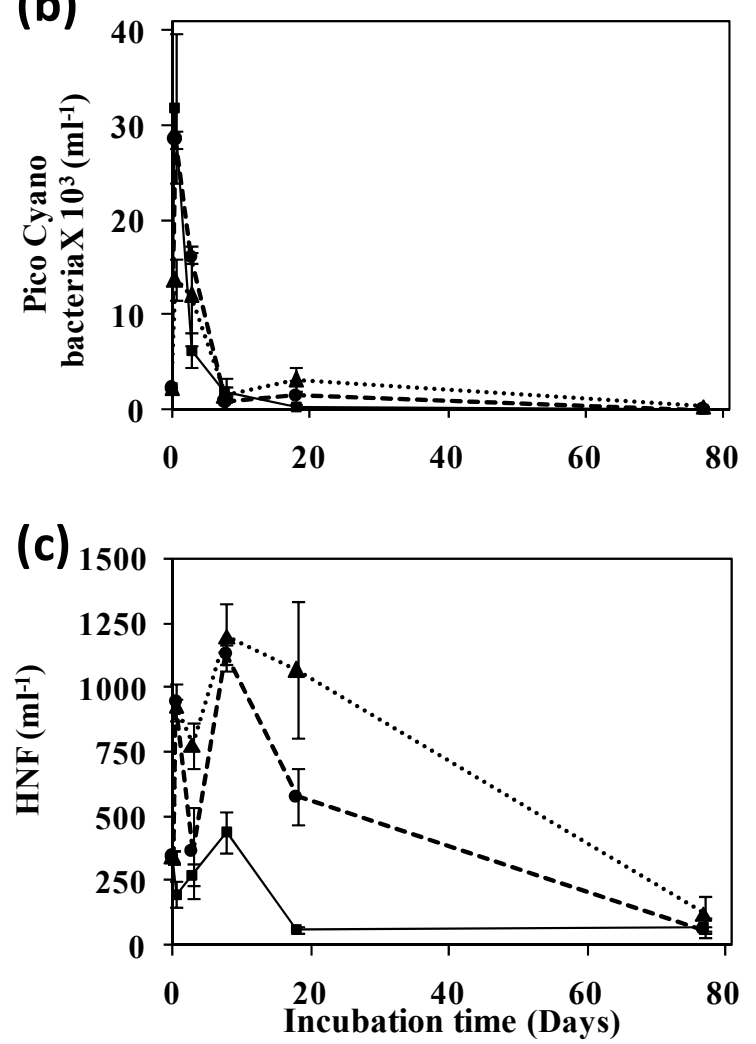

Figure 4. Changes of Heterotrophic (a) bacteria (b) pico-cyanobacteria (c) nano-flagelltes (HNF) abundance for light and dark during 78day incubation period with one day in-situ incubation and 77 days in laboratory dark condition. (RSW - ), and enriched coral mucus from Acropora digitifera (AcrRSW ..

Montepora digitata (MonRSW - - Concentrations indicated by mean with standard error. 